\title{
ANÁLISE MINERALÓGICA DE AMOSTRA DE AREIA DO AREAL MORRO BRANCO DO MUNICÍPIO DE PORTO GRANDE- AP
}

\section{ARTIGO ORIGINAL}

ANDRADE, Alexsandrea Ricarda Pinheiro ${ }^{1}$

PEREIRA, lara Rafaelle Silva ${ }^{2}$

DIAS, Claudio Alberto Gellis de Mattos ${ }^{3}$

FECURY, Amanda Alves ${ }^{4}$

DENDASCK, Carla Viana ${ }^{5}$

DANTAS, Antônio de Pádua Arlindo ${ }^{6}$

ANDRADE, Alexsandrea Ricarda Pinheiro. Et al. Análise mineralógica de amostra de areia do Areal Morro Branco do Município de Porto Grande- AP. Revista

${ }^{1}$ Técnica em Mineração. Instituto de Ensino Básico, Técnico e Tecnológico do Amapá (IFAP).

${ }^{2}$ Técnica em Mineração. Instituto de Ensino Básico, Técnico e Tecnológico do Amapá (IFAP).

${ }^{3}$ Biólogo, Doutor em Teoria e Pesquisa do Comportamento, Professor e pesquisador do Curso de Licenciatura em Química do Instituto de Ensino Básico, Técnico e Tecnológico do Amapá (IFAP).

${ }^{4}$ Biomédica, Doutora em Doenças Topicais, Professora e pesquisadora do Curso de Medicina do Campus Macapá, Universidade Federal do Amapá (UNIFAP).

${ }^{5}$ Teóloga, Doutora em Psicanálise, pesquisadora do Centro de Pesquisa e Estudos Avançados- CEPA.

${ }^{6}$ Tecnologia em Materiais. Mestre em Engenharia Mecânica, Professor e pesquisador do Curso de Licenciatura em Química do Instituto de Ensino Básico, Técnico e Tecnológico do Amapá (IFAP). 
Científica Multidisciplinar Núcleo do Conhecimento. Ano 05, Ed. 03, Vol. 11, pp. 1420. Março de 2020. ISSN: 2448-0959, Link de acesso: https://www.nucleodoconhecimento.com.br/meio-ambiente/analisemineralogica

\section{RESUMO}

O município de Porto Grande foi criado em $1^{\circ}$ de maio de 1992 e está localizado na região Norte do Estado de Amapá, possuindo uma área de $4400 \mathrm{~km}^{2}$. O objetivo deste trabalho é realizar a análise semiquantitativa de amostra de areia do Areal localizado no município de Porto Grande, a amostra coletada passou por algumas etapas fundamentais como: secagem, determinação de umidade, determinação das frações de argila, silte e areia, homogeneização, quarteamento e a análise granulométrica. $\mathrm{Na}$ determinação de umidade obtivemos o percentual de $2,4 \%$, sendo esta a diferença entre a massas úmida e a massa seca da nossa amostra P1, após o processo de peneiramento calculou-se a percentagem do material retido em cada peneira para analisarmos o desempenho do nosso peneiramento e por último foi realizado a determinação das frações de argila que teve como peso $0,17 \mathrm{~g}$, silte com peso de $24,83 \mathrm{~g}$ e a areia com peso $275 \mathrm{~g}$. Contudo ao final dos ensaios podemos observar uma anomalia nos resultados de análise de granulometria, devido ao fato da peneira em questão que estaria úmida, impedindo assim que passe todo o material de granulometria fina.

Palavras-chave: Análise Mineralógica, Porto Grande, areia.

\section{INTRODUÇÃO}

O estado do Amapá é uma das 27 unidades federativas do Brasil. O seu território é de $142.828,521 \mathrm{~km}^{2}$, sendo delimitado pelo estado do Pará a oeste e sul, pela Guiana Francesa a norte, o Oceano Atlântico a leste e o Suriname a noroeste. Dos 14,3 milhões de hectares que o estado possui $72 \%$ são destinados a unidades de conservação e terras indígenas). O estado abriga o maior parque nacional do país (Montanhas do Tumucumaque) (IBGE, 2018). 
O município de Porto Grande foi criado em $1^{\circ}$ de maio de 1992 e está localizado na região Norte do Estado de Amapá, possuindo uma área de $4400 \mathrm{~km}^{2}$. Economicamente, Porto Grande se destaca como grande produtor de frutas como abacaxi e laranja, além de milho. O funcionalismo público também movimenta a economia da região (IBGE, 2018).

A areia é um material de origem mineral finamente dividido em grânulos, composta basicamente por dióxido de silício, com 0,063 a $2 \mathrm{~mm}$. Forma-se à superfície da Terra pela fragmentação das rochas por erosão, por ação do vento ou da água, através de processos de sedimentação pode ser transformada em arenito (FERREIRA e DAITX, 2003).

Os depósitos de areia localizados no entorno da sede do Município de Porto Grande, estado do Amapá, na Latitude: 00 42' 48" N e Longitude: 51은 48" W com uma altitude: $60 \mathrm{~m}$ com uma área: $4421,6 \mathrm{Km} 2$ num raio de $4 \mathrm{~km}$, são constituídos por areia de granulometria média, quartzosos com espessura média de 8 a 10 metros, por vezes intercalados com lentes de areia fina ou material pelítico no decorrer da cobertura sedimentar fanerozóica compreendendo uma escala numérica 358-145 milhões de anos. A geometria, dimensões, cubagem e a origem desses depósitos ainda não são bem conhecidas, ocorrem próximos do contato da planície flúviocosteira amapaense com rochas intemperizadas do embasamento cristalino (OLIVEIRA, 2010).

São camadas com até 9 metros de espessura, compostas por areia branca friável, moderadamente a mal selecionada, com granulometria fina a média, por vezes, com grânulos maiores e até pequenos clastos. A mineralogia é essencialmente quartzosa, e os grãos são angulosos a sub-angulosos. São observadas estruturas sedimentares de tipo acamamento plano paralelo e estratificação cruzada tabular a tangencial de pequeno porte, com "set" de tamanhos variados, truncada por níveis enriquecidos em pequenos seixos(OLIVEIRA, 2010).

Por vezes pode ser observada a variação local para uma areia mais fina e mal selecionada, além da presença de camadas métricas (até 2 metros) e matacões de 
mesmo diâmetro, com material pelítico a areia fina em processo de oxidação e lateralização, que conferem um tom avermelhado (SHEPHERD e WALSH, 2002).

Existem diversos processos minerais para extração de areia na região e a atividade é bastante momentânea, sendo comum a paralisação temporária das empresas que extraem estes recursos em função da demanda do produto pelo mercado. O procedimento de lavra é moderadamente simples e corresponde ao desmonte mecânico com auxílio de pá carregadeira e carregamento direto em caminhão de transporte (SILVA et al., 2006).

\section{OBJETIVO}

Fazer a análise mineralógica de amostra de areia do Areal Morro Branco do município de Porto Grande- AP.

\section{MÉTODO}

\section{COLETA}

Foram coletadas manualmente 3 amostras de areia em três pontos, com pontos de elevações entre 71 e $81 \mathrm{~m}$, no areal Morro Branco, situado no município de Porto grande no Estado do Amapá, em 14 de setembro de 2018 (Figura 1).

Figura 1 Mostra a coleta manual das amostras de areia do areal Morro Branco do município de Porto Grande- AP.

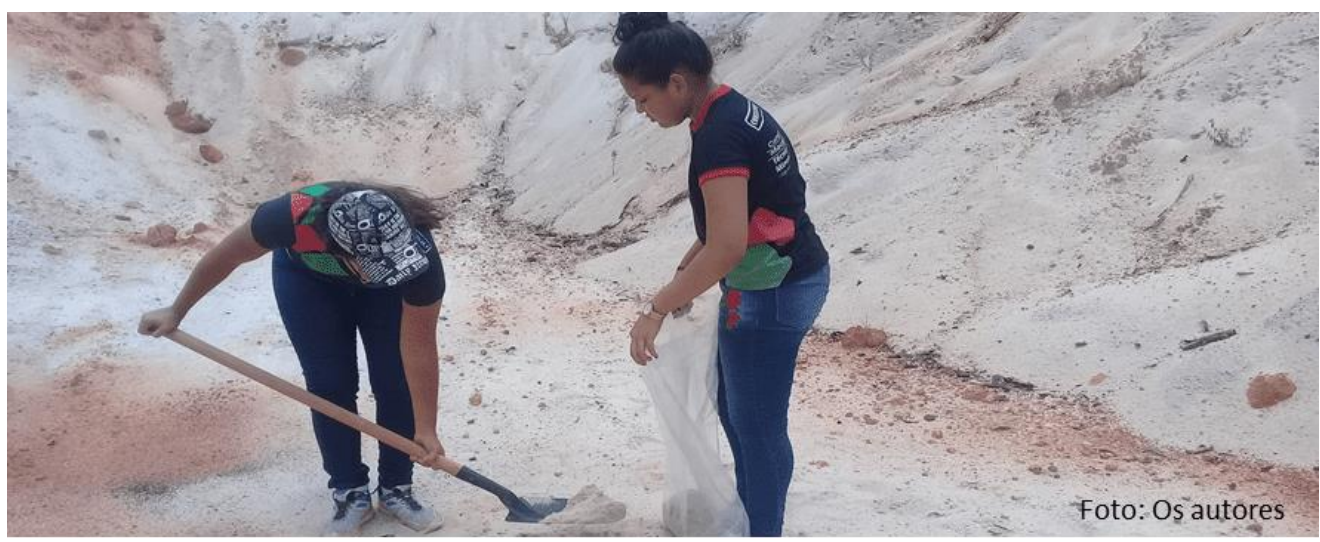




\section{SECAGEM}

Da amostra P1 foi selecionada $1 \mathrm{~kg}$ para ser levada a estufa, onde a mesma permaneceu por aproximadamente 24 horas, em um recipiente separado foi colocado o restante da amostra $\mathrm{P} 1$ que passou o mesmo período na estufa em uma temperatura entre $110^{\circ} \mathrm{C}$.

\section{DETERMINAÇÃO DE UMIDADE}

A amostra de $1 \mathrm{~kg}$ separada anteriormente foi retirada da estufa e pesada novamente, para obtermos a quantidade de umidade que a amostra teria perdido, para isso utilizamos a seguinte equação:

$$
\mathrm{U}=\frac{\mathrm{Mu}-\mathrm{Ms}}{\mathrm{Ms}}
$$

Onde: $\mathrm{U}=$ Umidade $/ \mathrm{Mu}=$ Massa Úmida $/ \mathrm{Ms}=$ Massa Seca

\section{HOMOGENEIZAÇÃO E QUARTEAMENTO}

O restante da amostra $\mathrm{P} 1$ que estava na estufa, foi retirada para que passasse pelos processos de homogeneização (Figura 2) e quarteamento (Figura 3), onde a homogeneização têm como objetivo obter uma distribuição mais uniforme dos constituintes, permitindo assim o quarteamento em frações menores. A operação de quarteamento é realizada com objetivo de reduzir a massa a ser manuseada para o processo, e tem como objetivo preparar a amostra para análise granulométrica química, mineralógica onde após estes processos retiramos uma amostra representativa de $1 \mathrm{~kg}$. 
Figura 2 Mostra o processo de homogeneização das amostras de areia do areal Morro Branco do município de Porto Grande- AP.

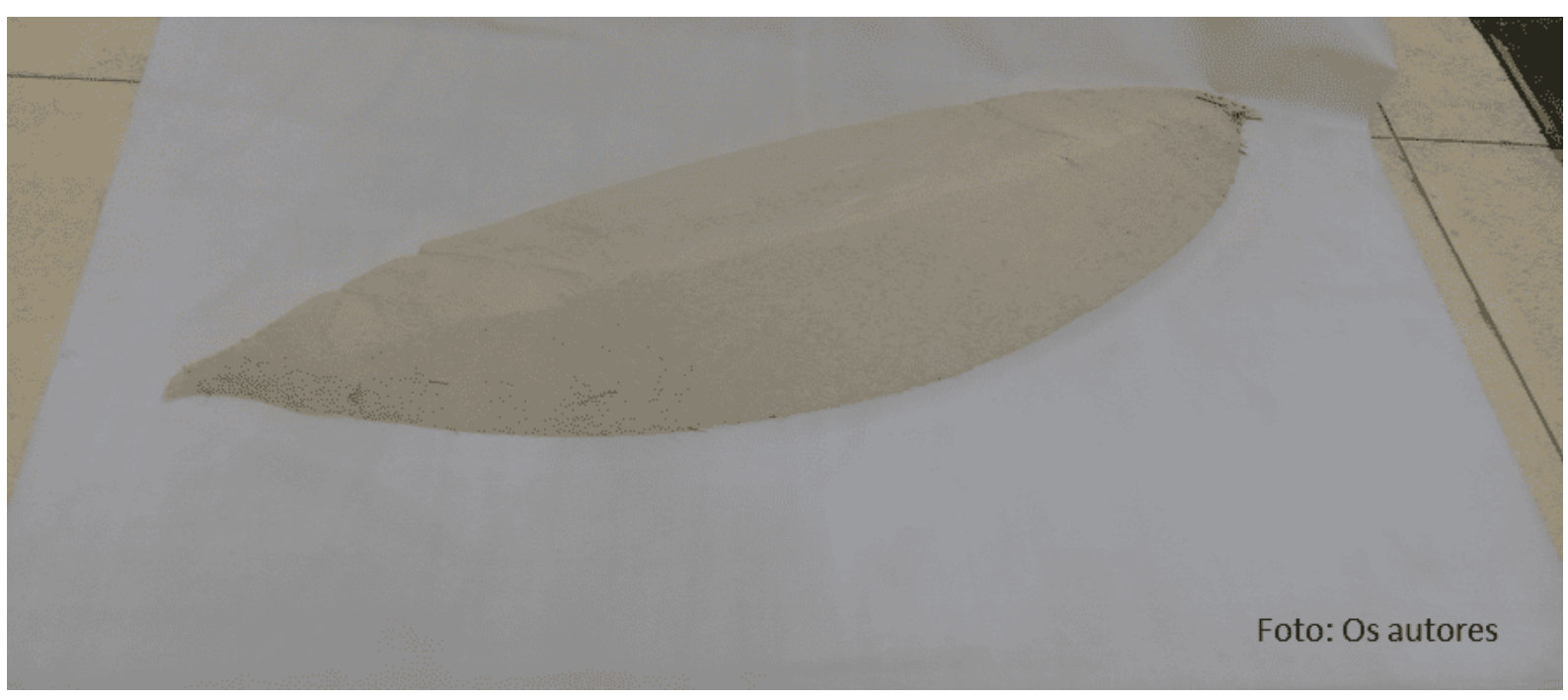

Figura 3 Mostra o processo de quarteamento das amostras de areia do areal Morro Branco do município de Porto Grande- AP.

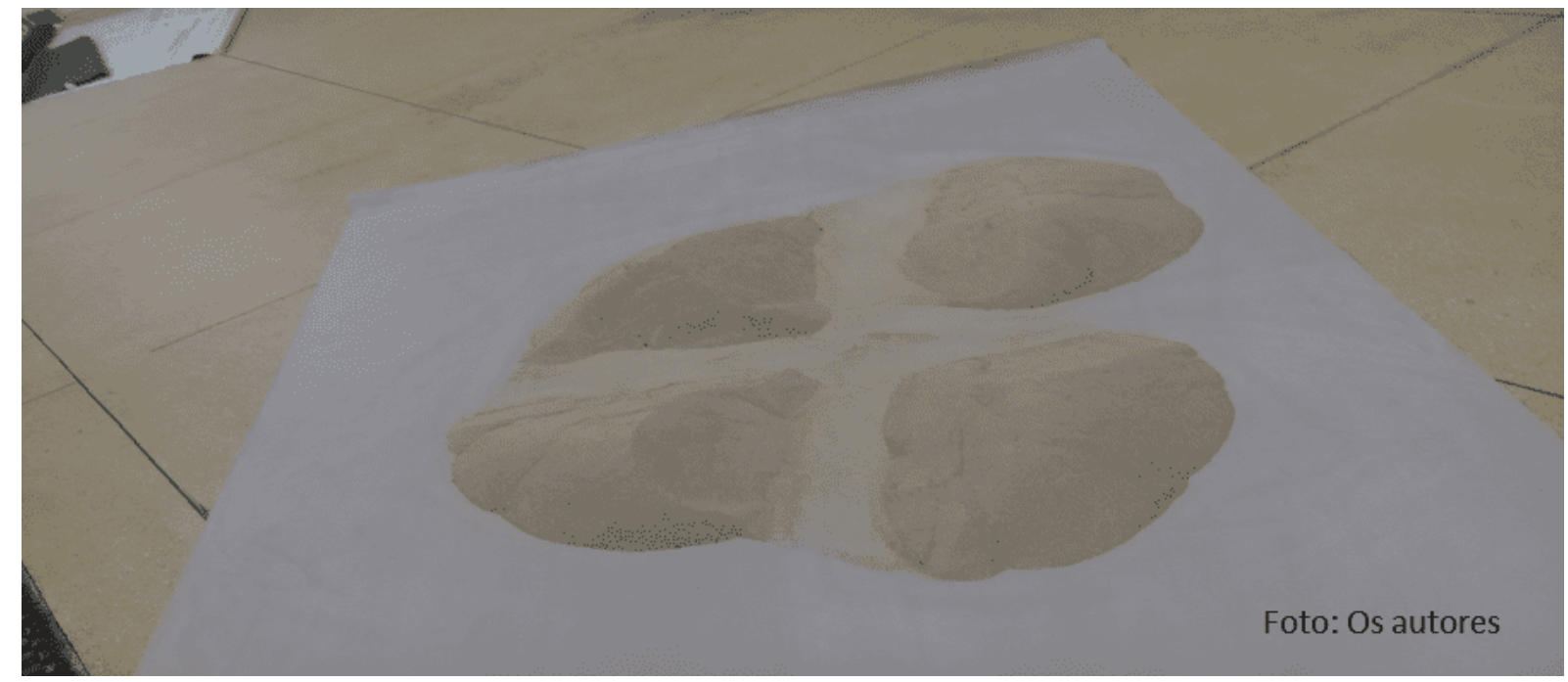

\section{SILICATO DE SÓDIO}

Foram separados $12,206 \mathrm{~g}$ de silicato de sódio que foi depositado em um balão volumétrico junto a $1 \mathrm{~L}$ de água destilada. Após isto foram retirados $10 \mathrm{~mL}$ desta solução com ajuda de uma pipeta e colocada em outro balão volumétrico de $100 \mathrm{ml}$. 


\section{DISPERSÃO MECÂNICA}

Retirou-se $300 \mathrm{~g}$ da amostra P1 e aproximadamente $7 \mathrm{~mL}$ da solução de silicato de sódio e colocou-se em um becker de $500 \mathrm{ml}$ e completou-se com água destilada em seguida essa mistura foi colocada em um agitador mecânico por aproximadamente 2 horas.

\section{ANÁLISE GRANULOMÉTRICA}

Foi feita a análise granulométrica da amostra $\mathrm{P} 1$ com o objetivo de determinar as dimensões das partículas que constituem a amostra. Com uma amostra representativa foi realizado o peneiramento a seco, através deste obtivemos a separação de partículas sólidas em frações de granulometrias diferentes, para tanto foram utilizadas peneiras com as seguintes aberturas, 8\# - 16\# - 35\# - 60\# - 80\# 100\# - 200\# - 250\# - 325\# e 400\#. Para posteriormente ser pesado para calcular percentual do retido acumulado e passante acumulado.

\section{DETERMINAÇÃO DAS FRAÇÕES ARGILA, SILTE E AREIA}

Para isto, $400 \mathrm{~g}$ da amostra $\mathrm{P} 1 \mathrm{com}$ isto foi submetida à dispersão em $250 \mathrm{~mL}$ de solução, com $4 \mathrm{~g}$ de hidróxido de sódio. Após a dispersão mecânica, utilizou-se uma peneira com malha de $270 \#$ de abertura para separar a fração areia total. O material retido na peneira foi lavado e seco em estufa a $105^{\circ} \mathrm{C}$ por 24 horas para, posteriormente ser pesado. O restante da suspensão, que consistia das frações silte e argila, foi recolhida em proveta de $1 \mathrm{~L}$ e o volume foi completado com água destilada. A suspensão foi homogeneizada por 1 hora e deixada em repouso por 24 horas para a sedimentação da fração silte. A fração argila foi estimada por meio de leitura de hidrômetro (densímetro) (BOUYOUCOS 1962). 


\section{RESULTADOS E DISCUSSÃO}

\section{DETERMINAÇÃO DA UMIDADE}

A Determinação de Umidade pode ser realizada de diversas formas, nesta análise utilizamos o teor de umidade natural da amostra P1, desta foi pesado 1046,35 g. Em seguida a amostra foi levada à estufa com temperatura de aproximada de $110^{\circ} \mathrm{C}$, onde permaneceu por 24 horas. Após ser retirada da estufa a amostra foi novamente pesada e obtida a massa seca de 1020,30 g, sendo a diferença entre a massas úmida e a seca o percentual de úmida que continha na amostra P1 como visto na equação:

\section{Umidade $=1046-1020 \times 100=2,4896 \%$ 1046}

\section{ANÁLISE GRANULOMÉTRICA}

Após o processo de peneiramento pesamos o material passante em cada peneira e calculamos as percentagens deste material.

Figura 4 Mostra material passante após peneiramento.

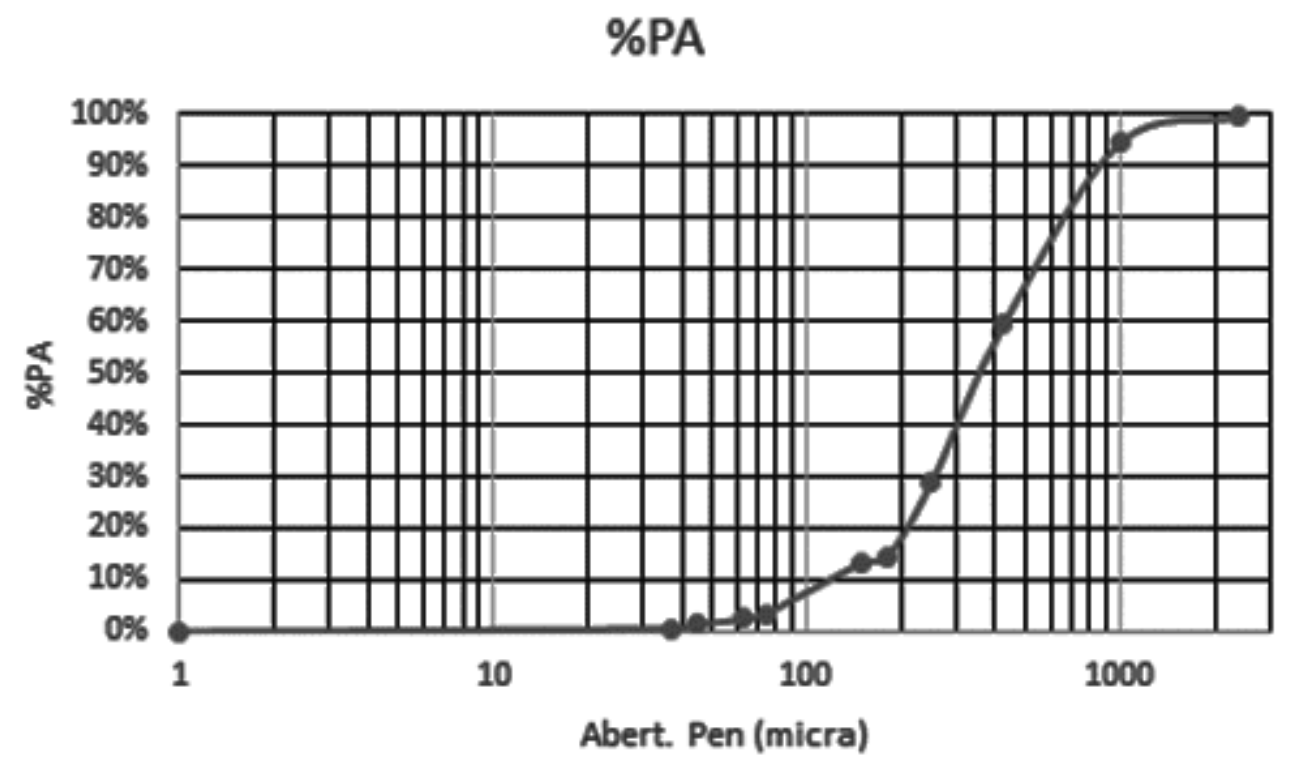


A peneira que teve o maior percentual de passante foi a de 8 \# onde passou $99,56 \%$, devido a granulometria da amostra ser fina. De acordo com a NBR 6457 - ABNT a granulometria fina é de 2 mm (ABNT, 2016).

\section{DETERMINAÇÃO DAS FRAÇÕES DE ARGILA, SILTE E A AREIA}

Análise para a determinação de frações de areia, argila e silte teve como resultado as respectivas massas de $275 \mathrm{~g}, 0,17 \mathrm{~g}$ e $24,83 \mathrm{~g}$, resultados corroborados pela literatura (SILVA et al., 2009).

\section{CONCLUSÃO}

Com a análise feita a amostra $\mathrm{P} 1$, constatamos que o percentual de umidade existente na amostra foi de 2,4\%, indicando que o local tem uma pequena incidência de umidade. Foi constatado também que devido a baixa granulometria da amostra, 99,56 $\%$ da amostra passou na peneira de 8\#. Com a determinação da fração de argila, silte e Areia chegaram-se as massas de $275 \mathrm{~g}, 0,17 \mathrm{~g}$ e 24,83g para areia, argila e silte respectivamente, indicando que a maior quantidade de material para essa amostra é de areia, existindo pouca quantidade de argila e relativa quantidade de silte. É necessário que seja feito um estudo mais aprofundado da amostra para determinação dos percentuais de quartzo e feldspato existentes nessa areia.

\section{REFERÊNCIAS}

ABNT. ABNT/ NBR 6457: amostra de solo: preparação para ensaios de compactação e ensaios de caracterização. Rio de Janeiro RJ: ABNT 2016.

BOUYOUCOS , G. J. Hydrometer method improved for making particle size analysis of soils. Agronomy Journal, v. 54, p. 464-465, 1962.

FERREIRA, G. C.; DAITX, E. C. A mineração de areia industrial na Região Sul do Brasil. Ouro Preto. R. Esc. Minas, v. 56, n. 1, p. 59-65, 2003. 
IBGE. Brasil em Síntese/Amapá/Porto Grande. 2018. Disponível em: < https://cidades.ibge.gov.br/brasil/ap/porto-grande/panorama >. Acesso em: 24 outubro 2018.

OLIVEIRA, M. J. D. DIAGNÓSTICO DO SETOR MINERAL DO ESTADO DO AMAPÁ. Macapá: IEPA, 2010. 148p.

SHEPHERD, K. D.; WALSH, M. G. Development of reflectance spectral libraries for characterization of soil properties. Soil Science Society of America Journal, v. 66, 2002.

SILVA, E. F. et al. Levantamento de reconhecimento de baixa intensidade dos solos do município de Aquidauana-MS. Rio De Janeiro RJ: Embrapa Solos, 2009.

SILVA, M. D. G. D. et al. Geologia e Recursos Minerais do Estado de Mato Grosso do Sul. Campo Grande MS: CPRM-SEPROTUR, 2006. 121.

Enviado: Março, 2020.

Aprovado: Março, 2020. 